\title{
CARACTERIZAÇÃO E DIVERGÊNCIA GENÉTICA DE ACESSOS DE Passiflora edulis e P. cincinnata COM BASE EM CARACTERÍSTICAS FÍSICAS E QUÍMICAS DE FRUTOS ${ }^{1}$
}

\author{
LARISSA BARBOSA DE SOUSA², ERISMAR MESQUITA SILVA ${ }^{3}$, \\ REGINA LUCIA FERREIRA GOMES ${ }^{4}$, ÂNGELA CELIS DE ALMEIDA LOPES 5 , \\ IZABEL CRISTINA VERAS SILVA ${ }^{6}$
}

RESUMO - A caracterização tem sido efetuada em Coleções de Germoplasma, gerando informações sobre a descrição e a classificação do material conservado, para subsidiar programas de melhoramento genético, por identificar indivíduos desejáveis e quantificar a diversidade disponível. Neste trabalho, objetivou-se caracterizar e quantificar a divergência genética de acessos de Passiflora edulis e $P$. cincinnata com base em características físicas e químicas de fruto. O material genético utilizado constou de seis acessos provenientes do Banco de Germoplasma da Universidade Estadual Paulista, Câmpus de Jaboticabal-SP. Os frutos foram avaliados com relação às características físicas: peso, tamanho e diâmetro do fruto, espessura da casca, número de sementes e rendimento de suco; e químicas: teor de sólidos solúveis e acidez total titulável. Os seis acessos diferiram com relação a todos os caracteres avaliados, indicando a presença de variabilidade genética e, consequentemente, a possibilidade de obtenção de ganhos genéticos com a seleção de genótipos superiores. A divergência genética entre os acessos foi analisada pelo método de agrupamento de Tocher, com o emprego da distância de Mahalanobis, como medida de dissimilaridade, formando-se dois grupos. As estimativas das correlações genéticas positivas mais elevadas, associadas ao rendimento de suco, foram com número de sementes/fruto, diâmetro do fruto, comprimento do fruto e peso do fruto. O método de Singh, utilizado para estimar a contribuição relativa de cada caráter na expressão da divergência genética entre os seis acessos, mostrou que o tamanho do fruto e o rendimento de suco foram as características que mais contribuíram, e que acidez total titulável apresentou menor contribuição.

Termos para indexação: Maracujazeiro, dissimilaridade, caracteres do fruto.

\section{CHARACTERIZATION AND GENETIC DIVERGENCE OF ACCESS OF Passiflora edulis and $P$. cincinnata BASED ON PHYSICAL AND CHEMICAL CHARACTERISTICS OF FRUITS}

\begin{abstract}
ABSTRAT - The characterizations have been performed in germplasm collections to generate information about the description and classification of collected materials, to discriminate more important characters and, mainly, to subsidize genetic breeding program by identifying desirable individuals as well as quantifying the available diversity. This study aimed to characterize and quantify the genetic divergence among accessions of Passiflora edulis and P. cincinnata based on physical and chemical characteristics of the fruits. The genetic material consisted of six accessions from the Germoplasm bank of UNESP in Jaboticabal. The fruits were evaluated with respect to the following physical characteristics: weight, length and fruit diameter, rind thickness, seed number and juice yield; and chemical: total soluble solids contents and total acidity. The six accessions differed with respect to all traits, indicating the presence of genetic variability and hence the possibility of obtaining genetic gains with selection of superior genotypes. The genetic diversity among the accessions was estimated by Tocher's grouping method, and used Mahalanobis' distance as a measure of dissimilarity, forming two groups. The estimates of higher positive genetic correlations associated with the juice, were with the number of seeds / fruit, fruit diameter, fruit length and fruit weight. The method of Singh, used to estimate the relative contribution of each character in the expression of genetic divergence among the six accessions, indicated that the size of the fruit and juice yield were the characteristics that contributed most, and total acidity showed a least contribution.
\end{abstract}

Index terms: Passiflora, dissimilarity, fruit characters.

\footnotetext{
${ }^{1}$ (Trabalho 052-12). Recebido em: 09-01-2012. Aceito para publicação em: 14-04-2012.

${ }^{2}$ Eng. Agr. Doutoranda em Fitotecnia, UFU. Uberlândia-MG. CEP: 38.400-902. E-mail: larissaufpi@ig.com.br

${ }^{3}$ Eng. Agr. Superintendência do INCRA. Cuiabá - MT. CEP: 78.050-970. E-mail: erismar.silva@cba.incra.gov.br

${ }^{4}$ Eng. Agr. D.Sc., Profa., Departamento de Fitotecnia, UFPI. Teresina - PI. CEP: 64.049-550. E-mail: rlfgomes@ufpi.edu.br

${ }^{5}$ Eng. Agr. D.Sc., Profa., Departamento de Biologia, UFPI. E-mail: acalopes@ufpi.edu.br

${ }^{6}$ Eng. Agr. M.Sc. em Ciência e Tecnologia de Alimentos, UFS. São Cristóvão - SE. CEP: 49.100-000. E-mail: izabelveras@hotmail.com
} 


\section{INTRODUÇÃO}

O gênero Passiflora é originário da América do Sul e tem, no Centro-Norte do Brasil, o maior centro de distribuição geográfica (LOPES, 1991). Contudo, somente algumas espécies desse gênero têm importância econômica em função da qualidade dos frutos para consumo ou por apresentarem propriedades medicinais. Assim, os cultivos comerciais de maracujazeiro compreendem basicamente o maracujazeiro-roxo (P. edulis Sims.) e o maracujazeiro-amarelo (P. edulis Sims.).

O maracujá é produzido no Equador, Colômbia, Peru, África do Sul e Austrália, sendo o Equador o maior exportador. Contudo, o Brasil é o maior produtor e consumidor mundial de maracujá, com uma área plantada de 35.600 ha, gerando aproximadamente 615.196 toneladas, de frutos em 2006 (IBGE, 2008). Em 2009, a produção foi de 718.798 toneladas numa área de 50.795 ha (IBGE, 2012). No País, o consumo do maracujá ocorre tanto da fruta in natura como de seus derivados e, para atender a uma demanda crescente, faz-se necessário estimular o avanço da cultura para outras regiões, não tradicionais em cultivo, e que devem apresentar condições edafoclimáticas que satisfaçam as necessidades inerentes ao bom desenvolvimento vegetativo e propiciem alta produtividade, criando, consequentemente, nova opção agrícola para a região (JORGE SOBRINHO, 2006).

A cultura adquiriu expressão econômica nacional a partir da década de 80 , inicialmente pelo incentivo da agroindústria, que estimulou o mercado do produto processado na forma de suco. Em seguida, a crescente demanda no mercado de fruta fresca ampliou significativamente o mercado interno. Assim, a partir de 1986, a cultura apresentou crescimento constante em áreas plantadas, resultante da popularização do consumo de frutas in natura nos grandes centros e consequente menor dependência das indústrias extratoras de suco (RIZZI et al., 1998).

Considerando que o maracujá é uma cultura ainda em expansão, pouco estudada, e em fase de domesticação, a cultura depara-se com fatores limitantes, como a baixa produtividade, causada, entre outros fatores, pela falta de genótipos altamente produtivos e pela grande variabilidade existente em pomares comerciais, o que reflete a necessidade do melhoramento genético (GONÇALVES et al., 2007).

Estudos mais aprofundados de caracterização agronômica e molecular de variedades comerciais de maracujá são necessários e de grande interesse para o melhoramento genético, orientando a escolha de genitores e o planejamento dos cruzamentos. Estudos preliminares têm mostrado que existe pouca variabilidade genética entre as cultivares para a resistência a doenças (JUNQUEIRA et al., 2003).

A caracterização físico-química tem sido efetuada em coleções de germoplasma para gerar informações sobre a descrição e a classificação do material conservado, na discriminação de caracteres mais importantes e, principalmente, para subsidiar programas de melhoramento genético por identificar indivíduos desejáveis e quantificar a diversidade disponível (JUNQUEIRA et al., 2005).

Uma ferramenta comumente utilizada no melhoramento são as análises multivariadas, visto que a análise univariada identifica apenas a existência de variabilidade entre indivíduos e os diferentes graus de discriminação dos mesmos, considerando cada descritor isoladamente. Para uma análise do poder discriminatório dos descritores, torna-se necessário analisar sua contribuição de forma conjunta. Sendo assim, as análises por graus de dissimilaridade, métodos de agrupamento e métodos aglomerativos podem ser aplicados, pois eles avaliam os indivíduos em vários aspectos (CRUZ et al., 2007).

Nesse sentido, objetivou-se realizar a caracterização física e química em frutos de acessos das espécies Passiflora edulis e P. cincinnata e estimar a divergência genética entre os acessos.

\section{MATERIAL E MÉTODOS}

O experimento foi conduzido em área experimental pertencente ao Departamento de Fitotecnia, Centro de Ciências Agrárias (CCA), da Universidade Federal do Piauí (UFPI), no município de Teresina - PI (1852S; 48²0’W e 805 m de altitude), em delineamento de blocos ao acaso, com três repetições, sendo três plantas por parcela. Foram avaliados os acessos: $P$. edulis (fruto grande), $P$. edulis (casca de ovo), $P$. cincinnata, $P$. edulis cv. Sul do Brasil, $P$. edulis f. flavicarpa Deg e P. kenia x P. edulis (geração $\mathrm{F}_{5}$ ), provenientes do Banco de Germoplasma da Universidade Estadual Paulista, Câmpus de Jaboticabal - SP, sendo o acesso $P$. cincinnata originado do Estado do Piauí.

Os frutos foram colhidos maduros, realizando-se a caracterização física e química no Núcleo de Estudos, Pesquisas e Processamento de Alimentos/ CCA/UFPI, em dez frutos por parcela, utilizando-se das seguintes características: peso do fruto $(\mathrm{PF})$, em gramas; comprimento do fruto (CF), diâmetro do fruto (DF) e espessura da casca (EC), em milímetros, determinados com paquímetro digital; número de sementes por fruto (NS), determinado por contagem manual; teor de sólidos solúveis (SS), dado em ${ }^{\circ}$ Brix 
a $20^{\circ} \mathrm{C}$, com o uso do refratométrico; acidez titulável (AT), expressa em g de ácido cítrico em $100 \mathrm{~g}$ de polpa, segundo normas do Instituto Adolfo Lutz (1985); e rendimento de suco, calculado pela relação entre o peso do suco e o peso dos frutos em análise (\%).

Os dados de cada característica foram submetidos à análise univariada, sendo que, na comparação entre as médias dos acessos, utilizou-se o teste de Tukey, a 5\% de probabilidade. Os coeficientes de correlação fenotípica, genética e de ambiente entre os pares de características foram estimados.

Na análise multivariada, a divergência genética entre os acessos foi estimada pelo método de agrupamento de Tocher (RAO, 1952), com o emprego da distância generalizada de Mahalanobis $\left(\mathrm{D}^{2}\right)$, como medida de dissimilaridade. Com base na matriz de distâncias, foi realizada também uma análise de agrupamento pelo algorítimo de classificação hierárquica ascendente UPGMA (Unweighted Pair Grouped Method Average). A identificação da importância das características foi feita com base no método de Singh (SINGH, 1981). As análises estatístico-genéticas foram realizadas com o auxílio do programa estatístico Genes (CRUZ, 2006).

\section{RESULTADOS E DISCUSSÃO}

Os acessos de $P$. edulis e $P$. cincinnata diferiram com relação à maioria das características avaliadas (Tabela 1), indicando a presença de variabilidade genética e, consequentemente, a possibilidade de obtenção de ganhos genéticos com a seleção de genótipos superiores. Quanto aos coeficientes de variação (CV), os valores mínimo e máximo observados foram de 4,54\% (comprimento do fruto) e 32,76\% (peso do fruto), confirmando a natureza complexa do caráter peso do fruto, cuja expressão é muito influenciada pelo ambiente.

Quanto ao comprimento do fruto, os acessos apresentaram variação de 50,36 a 91,21 mm, com média de $76,35 \mathrm{~mm}$, inferior à média encontrada por Abreu et al. (2009), de 82,26 mm, mas superior à encontrada por Medeiros (2005) de 72,20 mm. Para o diâmetro do fruto, a variação foi de 53,14 a 78,63 mm, com média de $68,72 \mathrm{~mm}$, superando os valores de 68,1 a 70,1 mm, encontrados por Lima et al. (2002), e a média de 66,70 mm, obtida por Veras (1997). Considerando essas características, os acessos que mais se destacaram foram: $P$. edulis (fruto grande), $P$. edulis cv. Sul do Brasil e P. edulis f. flavicarpa Deg, com as maiores médias, mostrando-se adequadas para a produção de frutos com características comerciais desejáveis.

Para espessura da casca, a média encontrada foi de 7,53 mm, com variação de 6,20 a 8,87 mm. Todos os acessos apresentaram média superior à encontrada por Abreu et al. (2009), de 6,33 mm. Logo, apresentaram casca um pouco mais grossa, o que representa mais descarte para o consumidor, mas, também, maior resistência mecânica ao transporte e manuseio. Para este caráter, há necessidade de se desenvolver um padrão, ainda inexistente, aliado a uma cavidade interna com maior rendimento em polpa, sem que isto signifique maior dano físico ao fruto, devido à baixa resistência da casca (mesocarpo).

Quanto ao peso do fruto, os valores mínimos e máximos foram de 74,41 g e 244,47 g, respectivamente, com média de 144,40 g, sendo superior às obtidas por Oliveira et al. (1988), que foi de 91,26 g.

Considerando o número de sementes por fruto, não houve diferença significativa entre os acessos. Resultado semelhante ao encontrado por Abreu et al. (2009), avaliando genótipos de maracujazeiro-azedo no Distrito Federal. Segundo Figueiredo et al. (1988), citados por Farias et al. (2007), as variações que ocorrem nas medidas físicas dos frutos são resultantes de diferenças no estádio de maturação, idade da cultura, latitude do local e condições edafoclimáticas.

Os valores determinados para sólidos solúveis, excetuando-se Passiflora cincinnata (maracujá-do-mato) que apresentou valor de 10,22 ${ }^{\circ}$ Brix, estiveram de acordo com os encontrados por Junqueira (2002), que avaliando onze cultivares de maracujazeiro obteve média de $13,19^{\circ}$ Brix, e também aos encontrados por Abreu et al. (2009), mas inferior ao encontrado por Veras (1997), com 18,4 ${ }^{\circ}$ Brix. No entanto, as médias de sólidos solúveis (SS) apresentadas pelos acessos estiveram acima dos exigidos pela indústria, que trabalha com uma faixa de 10 a 11,2 ${ }^{\circ}$ Brix. Quanto à acidez titulável, não foram encontradas diferenças entre os acessos, sendo que a média geral foi de 5,80, situando-se entre os valores de 3,76 \% e 6,60 \% obtidos por Lira Filho (1995).

O rendimento de suco apresentou média de $53,51 \%$, acima dos valores encontrados por Lipitoa e Robertson (1977), que encontraram rendimentos de aproximadamente $30,0 \%$ de suco. A média estimada neste trabalho foi superior também ao intervalo de $34,67 \%$ a 35,74 \%, obtido por Ritzinger et al. (1989); e de $20,0 \%$ a $30,0 \%$, determinado por Ruggiero et al. (1996).

As estimativas dos coeficientes de correlação fenotípica, genotípica e ambiental, entre as características do fruto de maracujazeiro (Tabela 2), mostraram que houve concordância de sinais nas correlações fenotípicas e genotípicas. As magnitudes das correlações genotípicas foram, em sua grande 
maioria, superiores às correlações fenotípicas, evidenciando a maior importância do componente genotípico em relação ao de ambiente, já que a correlação fenotípica é a soma desses dois componentes (CRUZ et al., 2007).

As estimativas das correlações fenotípicas entre as características avaliadas foram predominantemente significativas e de alta magnitude para a maioria, exceto para a correlação entre acidez titulável com as demais características. Morgado et al. (2010), em trabalho realizado com o objetivo de avaliar o grau de associação entre caracteres físico-químicos do maracujazeiro-azedo, também obtiveram resultado semelhante.

Em relação à correlação genotípica, que é a de maior importância para o melhoramento, observou-se variação de $-0,17$ a 0,99. O diâmetro equatorial do fruto apresentou maior correlação com o comprimento do fruto do que com o peso do fruto, embora a diferença tenha sido pequena (Tabela 2). Albuquerque et al. (2002) verificaram correlações entre rendimento de suco e peso da polpa, respectivamente, tanto com o diâmetro quanto com o comprimento do fruto, assim como observado neste trabalho. Oliveira (1980) verificou maior correlação entre o diâmetro equatorial do fruto com o peso do fruto, do que entre comprimento com o peso do fruto, em maracujazeiro-amarelo, diferenciando do encontrado neste trabalho, com maior correlação entre o diâmetro do fruto com o seu comprimento. Essas correlações são importantes, pois indicam que a seleção de plantas com frutos pesados poderá ser feita a partir da medição do tamanho e do diâmetro equatorial dos frutos, ainda no campo, sem a necessidade de pesá-los, o que pode facilitar muito os trabalhos de seleção.

No material genético estudado, a correlação entre rendimento de suco e relação diâmetro/ tamanho do fruto foi altamente significativa, o que comprova a hipótese de que frutos ovais têm maior rendimento de polpa (suco). Akamine et al. (1974) recomendam a seleção de plantas com frutos de forma ovalada por, supostamente, apresentarem maior teor de suco.

As correlações genéticas positivas mais elevadas, associadas ao caráter rendimento de suco, foram as seguintes: número de sementes/fruto $(0,95)$, diâmetro do fruto $(0,93)$, comprimento do fruto $(0,94)$ e peso do fruto $(0,90)$. Isso indica que essas características são as de maior importância na seleção de genótipos de maracujazeiro mais produtivos, através da seleção indireta.

Os valores dos coeficientes de correlação genética para a característica acidez total titulável mostraram-se negativos com a maioria das características avaliadas, excetuando-se o peso do fruto e o número de sementes/fruto.

As correlações ambientais foram altas nas associações entre o rendimento de suco com o comprimento do fruto e os diâmetro do fruto, e o diâmetro do fruto com o comprimento do fruto. Essas associações foram positivas, indicando que as características são influenciadas pelas mesmas diferenças nas condições ambientais. Entretanto, foram de menor magnitude que as correlações genotípicas, evidenciando que a relação entre as variáveis é mais influenciada por fatores herdáveis do que pelo ambiente (NEGREIROS et al., 2007).

As medidas de dissimilaridade entre os pares de acessos, expressas pela distância generalizada de Mahalanobis $\left(\mathrm{D}^{2}\right)$, indicaram que a distância mínima ocorreu entre $P$. edulis (Fruto grande) e $P$. edulis $\mathrm{f}$. flavicarpa Deg, (maracujá-amarelo) $\left(\mathrm{D}^{2}=16,78\right)$ e a máxima, entre $P$. cincinnata e $P$. edulis cv. Sul do Brasil $\left(D^{2}=612,74\right)$, sendo as mais divergentes (Tabela 3). O emprego das análises multivariadas, a partir das medidas de dissimilaridade, aumenta a probabilidade de se recuperar genótipos superiores nas gerações segregantes (CARVALHO et al., 2003), sobretudo quando se utilizam indivíduos de grupos mais afastados, gerados por estas análises. O que mais se busca é recomendar cruzamentos entre genótipos divergentes, mas que também apresentem desempenho superior com relação aos principais caracteres de importância econômica; logo, deve-se considerar, também, os comportamentos per se na escolha dos genótipos (ABREU et al., 2004).

Na análise de agrupamento dos acessos pelo método de Tocher, observou-se a formação de dois grupos de dissimilaridade, sendo o grupo 1 formado pelos acessos da espécie $P$. edulis, e o grupo 2, pelo acesso da espécie $P$. cincinnata, que divergiu das demais por apresentar as menores médias para as características avaliadas, exceto para acidez titulável. O método hierárquico UPGMA (Unweighted Pair-Group Average) também possibilitou a formação de dois grupos, concordando com o resultado obtido pelo método de Tocher.

Considerando o desempenho dos acessos, as medidas de dissimilaridade e os grupos estabelecidos pelo método de Tocher, verificou-se que os cruzamentos entre $P$. edulis (Fruto grande) com $P$. edullis (Casca-de-ovo), e $P$. edulis $f$. flavicarpa Deg com a geração resultante do cruzamento entre $P$. kenia $x$ $P$. edulis constituem boas opções para obtenção de populações segregantes, com altos teores de sólidos solúveis, peso, tamanho e diâmetro de fruto.

O método de Singh (1981), utilizado para 
estimar a contribuição relativa de cada caráter na expressão da divergência genética (Tabela 4), indicou que o tamanho do fruto $(54,29 \%)$, o rendimento de suco (16,85\%) e o diâmetro de fruto (15,94 \%) foram os caracteres que mais contribuíram para a divergên- cia total. As contribuições dos caracteres espessura da casca (5,38\%), sólidos solúveis (2,93\%), número de sementes/fruto (2,52\%) e peso do fruto $(1,88 \%)$ foram baixas, sendo que a menor contribuição foi da acidez titulável (0,20\%).

TABELA 1- Médias ${ }^{1}$ das características: comprimento do fruto (CF), diâmetro do fruto (DF), espessura da casca (EC), peso do fruto (PF), número de sementes por fruto (NS), teor de sólidos solúveis totais (SS), acidez titulável (AT) e rendimento de suco (RS), avaliados em Teresina - PI. 2011.

\begin{tabular}{|c|c|c|c|c|c|c|c|c|}
\hline Acesso $^{2}$ & CF (mm) & $\mathrm{DF}(\mathrm{mm})$ & $\mathrm{EC}(\mathrm{mm})$ & PF (g) & NS & SS ( ${ }^{\circ}$ Brix) & AT (\%) & RS (\%) \\
\hline 1 & $87,48 a$ & 71,97ab & 7,63abc & $244,47 a$ & $290,35 a$ & $14,04 a$ & $6,4 a$ & 39,36a \\
\hline 2 & $69,44 b$ & $66,21 b c$ & $6,48 b c$ & $103,57 b$ & $221,53 a$ & $13,21 \mathrm{ab}$ & $5,3 a$ & $56,84 a$ \\
\hline 3 & $50,36 b$ & $53,14 c$ & $6,20 c$ & $74,41 b$ & $170,10 \mathrm{a}$ & $10,22 b$ & $6,6 a$ & $58,77 a$ \\
\hline 4 & $91,21 \mathrm{a}$ & $78,47 \mathrm{abc}$ & 7,74abc & 170,39ab & $226,85 a$ & 13,13ab & $6,4 a$ & $56,85 a$ \\
\hline 5 & $89,70 a$ & 78,63a & 8,87a & 184,36ab & $249,59 a$ & $14,04 \mathrm{a}$ & 5,3a & $56,70 a$ \\
\hline 6 & $69,81 b$ & $63,92 b$ & $8,25 a b$ & 89,23b & $191,61 \mathrm{a}$ & $14,37 a$ & $4,8 \mathrm{a}$ & $52,54 a$ \\
\hline Média geral & 76,35 & 68,72 & 7,53 & 144,40 & 225,00 & 13,20 & 5,8 & 53,21 \\
\hline CV (\%) & 4,54 & 4,69 & 8,99 & 32,76 & 23,28 & 9,43 & 2,9 & 18,30 \\
\hline
\end{tabular}

${ }^{1}$ Médias seguidas pela mesma letra, em cada coluna, não diferem entre si pelo teste de Tukey $(\mathrm{P}<0,05)$.

${ }^{2} 1$ - P. edulis (Fruto grande), 2 - P. edulis (Casca de ovo), 3 - P. cincinnata, 4 - P. edulis cv. Sul do Brasil, 5 - P. edulis Sims f. flavicarpa Deg, 6 - P. kenia x P. edulis.

TABELA 2 - Estimativas dos coeficientes de correlação fenotípica $\left(\mathrm{r}_{\mathrm{F}}\right)$, genotípica $\left(\mathrm{r}_{\mathrm{G}}\right)$ e ambiental $\left(\mathrm{r}_{\mathrm{A}}\right)$ entre as características (CARACT): peso do fruto $(\mathrm{PF})$, comprimento do fruto $(\mathrm{CF})$, diâmetro do fruto (DF), espessura da casca (EC), número de sementes/fruto (NS), sólidos solúveis ( $\left.{ }^{\circ} \mathrm{BRIX}\right)$, acidez total (AT) e rendimento de suco (RS) dos acessos de Passiflora sp. Teresina - PI, 2011.

\begin{tabular}{|c|c|c|c|c|c|c|c|c|}
\hline CARACT & & CF & DF & $\mathrm{EC}$ & NS & SS & $\mathrm{AT}$ & RS \\
\hline \multirow[t]{3}{*}{$\overline{P F}$} & $\mathrm{r}_{\mathrm{F}}$ & $0,85 * *$ & $0,75 * *$ & $0,49 *$ & $0,95 * *$ & $0,55^{*}$ & $0,32^{\mathrm{ns}}$ & $0,85 * *$ \\
\hline & $r_{G}$ & $0,91++$ & $0,82++$ & $0,49+$ & $0,97++$ & $0,61++$ & $0,87++$ & $0,90++$ \\
\hline & $\mathrm{r}_{\mathrm{A}}$ & $0,49+$ & $0,25^{\text {ns }}$ & $0,47+$ & $0,43^{\mathrm{ns}}$ & $0,25^{\mathrm{ns}}$ & $-0,25^{\mathrm{ns}}$ & $0,56+$ \\
\hline \multirow[t]{3}{*}{ CF } & $r_{F}$ & & $0,98 * *$ & $0,72 * *$ & $0,81 * *$ & $0,73 * *$ & $-0,02^{\text {ns }}$ & $0,92 * *$ \\
\hline & $r_{G}^{F}$ & & $0,98++$ & $0,77++$ & $0,97++$ & $0,80++$ & $-0,17^{\mathrm{ns}}$ & $0,94++$ \\
\hline & $\mathrm{r}_{\mathrm{A}}$ & & $0,80++$ & $0,79++$ & $0,27^{\mathrm{ns}}$ & $0,53+$ & $0,30^{\text {ns }}$ & $0,89++$ \\
\hline \multirow[t]{3}{*}{$\mathrm{DF}$} & $r_{F}$ & & & $0,71^{* *}$ & $0,72 * *$ & $0,68 * *$ & $-0,09^{\mathrm{ns}}$ & $0,93 * *$ \\
\hline & $r_{G}$ & & & $0,75++$ & $0,99++$ & $0,74++$ & $-0,29$ & $0,95++$ \\
\hline & $\mathrm{r}_{\mathrm{A}}$ & & & $0,45^{\text {ns }}$ & $0,62++$ & $0,38^{\text {ns }}$ & $-0,92++$ & $0,89++$ \\
\hline \multirow[t]{3}{*}{ EC } & $r_{F}$ & & & & $0,43^{\text {ns }}$ & $0,76 * *$ & $-0,45^{\mathrm{ns}}$ & $0,61^{* *}$ \\
\hline & $r_{G}$ & & & & $0,70++$ & $0,90++$ & $-0,89++$ & $0,63++$ \\
\hline & $\mathrm{r}_{\mathrm{A}}$ & & & & $0,22^{\text {ns }}$ & $0,08^{\mathrm{ns}}$ & $-0,42$ & $0,49+$ \\
\hline \multirow[t]{3}{*}{ NS } & $\mathrm{r}_{\mathrm{F}}$ & & & & & $0,65 * *$ & $0,14^{\mathrm{ns}}$ & $0,77 * *$ \\
\hline & $r_{G}$ & & & & & $0,85++$ & 0,93++ & $0,95++$ \\
\hline & $\mathrm{r}_{\mathrm{A}}$ & & & & & $0,46^{\mathrm{ns}}$ & $-0,18^{\mathrm{ns}}$ & $0,63++$ \\
\hline \multirow[t]{3}{*}{ SS } & $\mathrm{r}_{\mathrm{F}}$ & & & & & & $-0,56^{*}$ & $0,47^{*}$ \\
\hline & $r_{G}$ & & & & & & $-0,67++$ & $0,48+$ \\
\hline & $\mathrm{r}_{\mathrm{A}}$ & & & & & & $-0,02^{\mathrm{ns}}$ & $0,39^{\text {ns }}$ \\
\hline \multirow[t]{3}{*}{ AT } & $r_{F}$ & & & & & & & $0,18^{\text {ns }}$ \\
\hline & $r_{G}$ & & & & & & & $0,46^{\mathrm{ns}}$ \\
\hline & $r_{A}$ & & & & & & & $0,06^{\mathrm{ns}}$ \\
\hline
\end{tabular}

**, *, ns: significativo a $1 \%$ e $5 \%$ de probabilidade, e não significativo, respectivamente, pelo teste t.

$++;+,{ }^{n}$ : significativo a $1 \%$ e $5 \%$, e não significativo, respectivamente, pelo método de bootstrap com 10 mil simulações. 
TABELA 3 - Medida de dissimilaridade genética entre seis acessos do gênero Passiflora, utilizando a distância generalizada de Mahalanobis. Teresina - PI, 2011.

\begin{tabular}{crrrrr}
\hline Acesso $^{1}$ & 2 & 3 & \multicolumn{1}{c}{4} & \multicolumn{1}{c}{5} & \multicolumn{1}{c}{6} \\
\hline 1 & 105,40 & 486,50 & 49,21 & 16,78 & 68,31 \\
2 & & 223,87 & 112,24 & 105,72 & 37,88 \\
3 & & & 612,74 & 528,30 & 362,37 \\
4 & & & & 23,19 & 190,75 \\
5 & & & & & 97,03 \\
\hline
\end{tabular}

${ }^{1} 1$ - P. edullis (fruto grande), 2 - P. edullis (casca de ovo), 3 - P. cincinnata, 4 - P. edulis (fruto amarelo), 5 - P. edulis Sims f. flavicarpa Deg, 6 - P. kenia $\mathrm{x}$ P. edullis.

TABELA 4- Contribuição relativa das características físicas e químicas para divergência genética entre os seis acessos de Passiflora, pelo método proposto por Singh (1981). Teresina - PI, 2011.

\begin{tabular}{lc}
\hline Características & Valor \% \\
\hline Tamanho do fruto & 54,30 \\
Rendimento de suco & 16,85 \\
Diâmetro do fruto & 15,94 \\
Espessura da casca & 5,38 \\
Sólidos solúveis & 2,93 \\
No de sementes/fruto & 2,52 \\
Peso do fruto & 1,88 \\
Acidez titulável & 0,20 \\
\hline
\end{tabular}

\section{CONCLUSÃO}

Os acessos de $P$. edulis e $P$. cincinnata analisados neste trabalho apresentam variabilidade genética para a maioria das características estudadas, possibilitando a seleção de genitores divergentes com relação às características físicas e químicas dos frutos. As características de maior importância na seleção de genótipos de maracujazeiro são: número de sementes, diâmetro do fruto, tamanho do fruto e peso do fruto, sendo que tamanho do fruto, rendimento de suco e diâmetro do fruto são as que mais contribuem para a divergência total entre os acessos de Passiflo$r a$, e a que menos contribui é acidez titulável.

\section{REFERÊNCIAS}

ABREU, F.B.; LEAL, N.R.; RODRIGUES, R.; AMARAL JR.; A.T.; SILVA, D.J.H. Divergência genética entre acessos de feijão-de-vagem de crescimento indeterminado. Horticultura Brasileira, Brasília, v.22, n.3, p.547-552, 2004.
ABREU, S.P.M.; PEIXOTO, J.R.; JUNQUEIRA, N.V.; SOUSA, M.A.F. Características físico-químicas de cinco genótipos de maracujazeiro-azedo cultivados no Distrito Federal. Revista Brasileira de Fruticultura, Jaboticabal, v. 31, n. 2, p. 487491, 2009.

AKAMINE, E.K.; ARAGAKI, M.; BEAUMONT, J.H.; BOWERS, F.A.I.; HAMILTON, R.A.; NISHIDA, T; SHERMAN, G.D.; SHOJI, K.; STOREY, W.B.; MARTINEZ, AP.; YEE, W.Y.J.; ONSDORFF, T.; SHAN, T.N. Passion fruit culture in Hawaii. Hawaii: University of Hawaii, 1974. 35p. (Circular, 345)

ALBUQUERQUE, A.S.; BRUCKNER, C.H.; CRUZ, C.D.; CASALI, V.W.D.; ARAÚJO, R. da C.; MOREIRA, A.E.; SOUZA, J.A. de. Possibilidade de seleção indireta para peso do fruto e rendimento em polpa em maracujá (Passiflora edulis Sims). In: CONGRESSO BRASILEIRO DE FRUTICULTURA, 17., 2002, Belém. Anais... Belém: Embrapa, 2002. CD-ROM.

CARVALHO, L. P. DE; LANZA, M. A.; FALLIERI, J.; SANTOS, J. W. DOS. Análise da diversidade genética entre acessos de banco de germoplasma de algodão. Pesquisa Agropecuária Brasileira, Brasília, v. 38, n.10, p. 1149-1155, 2003. 
CRUZ, C. D. Programa genes: análise multivariada e simulação. Viçosa: UFV, 2006. 175p.

CRUZ, C.; REGAZZI, A. J.; CARNEIRO, P. C. S. Modelos biométricos aplicados ao melhoramento genético. 3.ed. Viçosa: UFV, 2007. 480p.

FARIAS, J.F.; SILVA, L.J.B. ARAÚJO NETO, S.E.; MEDONÇA, V. Qualidade do maracujá-amarelo comercializado em Rio Branco, Acre. Revista Caatinga, Mossoró, v.20, n.3, p.196-202, 2007.

GONÇALVES, G.M.; VIEIRA, A.P.; BEZERRA NETO, F.V.; PEREIRA, M.G.; PEREIRA, T.N.S. Seleção e herdabilidade na predição de ganhos genéticos em maracujá-amarelo. Pesquisa Agropecuária Brasileira, Brasília, v.42, n.2, p.193-198, fev. 2007.

IBGE - Instituto Brasileiro de Geografia e Estatística. Diretoria de Pesquisas, Coordenação de Agropecuária, Produção Agrícola Municipal, 2009. v.36. Disponível em: <www.ibge.gov.br/>. Acesso em: 10 fev. 2012.

IBGE - Instituto Brasileiro de Geografia e Estatística. Produção e área de produção de maracujá: 2000 a 2006. Brasília. Disponível em: < $\underline{w w w . i b g e . g o v . b r} />$. Acesso em: 10 jan. 2008.

INSTITUTO ADOLFO LUTZ. Normas analíticas do Instituto Adolfo Lutz: métodos químicos e físicos para análises de alimentos. 3.ed. São Paulo: Coordenadoria dos serviços técnicos especializados - Secretaria do Estado da Saúde, 1985. 533p.

JORGE SOBRINHO, J. Avaliação de genótipos de maracujazeiro amarelo (Passiflora edulis $f$. flavicarpa Deg.) no município de Poxoréu - MT. 2006. 297 f. Dissertação (Mestrado) - Universidade Federal do Mato Grosso, Cuiabá, 2006.

JUNQUEIRA, N.T.V. Manejo integrado de doenças do maracujazeiro, da mangueira, da goiabeira e das anonáceas. In: ZAMBOLIM, L. (Ed.). Manejo integrado de doenças e pragas de fruteiras tropicais. Viçosa-MG: UFV, 2002. p.239-273.

JUNQUEIRA, NT.V.; ANJOS, J. R. N.; SILVA, A. P. O.; CHAVE, R. C.; GOMES, A.C. Reação às doenças e produtividade de onze cultivares de maracujazeiro-azedo cultivadas sem agrotóxico. Pesquisa Agropecuária Brasileira, Brasília, v.38, n.8, p. 1005-1010, 2003.
JUNQUEIRA, N. T. V.; BRAGA, M. F.; FALEIRO, F. G.; PEIXOTO, J. R.; BERNACCI, L. C. Potencial de espécies silvestres de maracujazeiro como fonte de resistência a doenças. In: FALEIRO, F. G.; JUNQUEIRA, N. T. V.; BRAGA, M. F. Maracujá: germoplasma e melhoramento genético. Planaltina: Embrapa Cerrados, 2005. p. 81-106.

LIMA, A.A.; CALDAS, R.C.; BORGES, A.L.; RITZINGER, C.H.S.P.; TRINDADE, A.V.; PIRES, M.M.; MIDLEJ, M.M.B.C.; MATA, H.T.C.; SOUZA, J.S. Cultivos intercalares e controle de plantas daninhas em plantios de maracujá amarelo. Revista Brasileira de Fruticultura, Jaboticabal, v. 24, n.3, p. 711- 713, 2002.

LIPITOA, S.; ROBERTSON, G. L. The enzymatic extraction of juice from yellow passion fruit pulp. Tropical Science, London , v. 19, n. 2, p. 105-112, 1977.

LIRA FILHO, J. F. de. Utilização da casca do maracujá amarelo (Passiflora edulis f. flavicarpa Degener) na produção de geléia. 1995. 132 f. Dissertação (Mestrado em Tecnologia de Alimentos) - Universidade Estadual de Campinas, Campinas, 1995.

LOPES, S. C. Citogenética do maracujá, Passiflora spp. In: SÃO JOSÉ, A.R. A cultura do maracujá no Brasil. Jaboticabal: FUNEP, 1991. p. 201-209.

MEDEIROS, S. A. F. Desempenho agronômico e caracterização físico-química de genótipos de maracujá-roxo e maracujá-azedo no Distrito Federal. 2005. 95 f. Dissertação (Mestrado em Ciências Agrárias) - Faculdade de Agronomia e Medicina Veterinária, Universidade de Brasília, Brasília,2005.

MORGADO, M .A. P.; SANTOS, C. E. M.; LINHARES, H.; BRUCKNER, C. H. Correlações fenotípicas em características fisicoquímicas do maracujazeiro-azedo. Acta Agronômica, Colombia, v.59, n.4, p 457-461, 2010.

NEGREIROS, J. R. DA S.; ÁLVARES, V. de S.; BRUCKNER, C. H.; MORGADO, M. A. D.; CRUZ, C. D. Relação entre características físicas e o rendimento de polpa de maracujá-amarelo. Revista Brasileira de Fruticultura, Jaboticabal, v. 29, n. 3, p. 540-545, 2007. 
OLIVEIRA, J. C. de. Melhoramento genético de Passiflora edulis f. flavicarpa Deg. visando ao aumento de produtividade. 1980. 133f. Tese (Livre-Docência) - Faculdade de Ciências Agrárias e Veterinárias, Universidade Estadual Paulista, Jaboticabal, 1980.

OLIVEIRA, J. C.; FERREIRA, F.R.; RUGGIERO, C.; NAKAMURA, K. Caracterização e avaliação de germoplasma de Passiflora edulis. In: CONGRESSO BRASILEIRO DE FRUTICULTURA, 9., 1988, Campinas, Anais... Campinas: Sociedade Brasileira de Fruticultura, 1988. v. 2, p. 591-595.

RAO, R.C. Advanced statistical methods in biometric research. New York: John Wiley, 1952. 390p.

RITZINGER, R.; MANICA, I.; RIBOLDI, J. Efeito do espaçamento e da época de colheita sobre a qualidade do maracujá-amarelo. Pesquisa Agropecuária Brasileira, Brasília, v. 24, n. 2, p. 241-245, fev., 1989.

RIZZI, L.C.; RABELLO, L.R.; MOROZINI FILHO, W.; SAVASAKI, E.T.; KAVATI, R. Cultura do maracujá azedo. Campinas: CATI, 1998. 53p. (Boletim Técnico, 235).
RUGGIERO, C.; SÃO JOSE, A.R.; VOLPE, C.A.; OLIVEIRA, J.C.; DURIGAN, J.F.; BAUMGARTNER, J.G.; SILVA, J.R.; MAKAMURA, K.I.; FERREIRA, M.E.; KAVATI, R.; PEREIRA, V. Maracujá para exportação: aspectos técnicos da produção. Brasília: EMBRAPA-SPI, 1996. 64p. (Publicações técnicas FRUPEX, 19).

SINGH, D. The relative importance of characters affecting genetic divergence. Indian Journal of Genetic and Plant Breeding, New Delhi, v. 41, n. 2, p. 237-245, 1981.

VERAS, M.C.M. Fenologia, produção e caracterização físico-química dos maracujazeiros ácido (Passiflora edulis f. flavicarpa Deg.) e doce (Passiflora alata Dryand) nas condições de cerrado de Brasília-DF. 1997. 105f. Dissertação (Mestrado em Agronomia, Área de Fitotecnia) - Universidade Federal de Lavras, Lavras, 1997. 